\title{
ACTITUDES LINGÜÍSTICAS EN EL VOCABULARIO DE MEJICANISMOS DE JOAQUÍN GARCÍA ICAZBALCETA (1899)
}

\author{
LANGUAGE ATTITUDES IN THE \\ VOCABULARIO DE MEJICANISMOS BY JOAQUÍN \\ GARCÍA ICAZBALCETA (1899)
}

\author{
Ivo BuzeK \\ Masarykova univerzita \\ ibuzek@phil.muni.cz
}

\begin{abstract}
RESUMEN: En el presente artículo se estudian las actitudes lingüísticas hacia el español mexicano que se encuentran en el diccionario de Joaquín García Icazbalceta. Seguiremos aquí el modelo de actitudes lingüísticas de López Morales (1991), complementado por los enfoques de sociolingüística histórica resumidos en Milroy (2014) y Langer y Nesse (2014). Nos centraremos en las actitudes que se formulan en las definiciones. El objetivo del estudio será identificar los patrones de actitudes positivas y negativas tal como se expresan en la obra. Intentaremos demostrar que la clave reside en el hecho de considerar el español mexicano como una variedad nacional que está a la par del estándar europeo, o “académico". En este sentido, el diccionario de García Icazbalceta sería una de las primeras manifestaciones de la identidad nacional (y lingüística) mexicana en el ámbito de la lexicografía.
\end{abstract}

Palabras clave: Joaquín García Icazbalceta; lexicografía; sociolingüística histórica; actitudes lingüísticas; español mexicano.

Abstract: This article studies the linguistic attitudes towards Mexican Spanish that are found in Joaquín García Icazbalceta's dictionary. We follow the model of linguistic attitudes formulated by López Morales (1991), aided by approaches to historical sociolinguistics summarized in Milroy (2014) and Langer and Nesse (2014). We focus on the attitudes formulated in definitions. The aim of our study is to identify the patterns of positive and negative attitudes as expressed in the dictionary. We will try to underline a desire to consider Mexican Spanish to be a national variation as valid as the European, or "academic", standard. In this sense, García Icazbalceta's dictionary can be considered to be one of the first manifestations of a Mexican national (and linguistic) identity in the field of lexicography.

Keywords: Joaquín García Icazbalceta; lexicography; historical socio-

linguistics; language attitudes; Mexican Spanish.

Recepción: 22 de julio de 2018; aceptación: 27 de marzo de 2019. 


\section{INTRODUCCIÓN*}

En la historiografía de la lingüística mexicana, y en la de la lingüística hispánica en un sentido más amplio, hay obras que muchos identifican, pero que son, de hecho, bastante poco conocidas en profundidad. Éste es precisamente el caso del Vocabulario de mejicanismos comprobado con ejemplos y comparado con los de otros países hispano-americanos, obra póstuma y desgraciadamente inconclusa de Joaquín García Icazbalceta (1899), sobre la que hay pocos estudios detallados y bien contextualizados ${ }^{1}$. El único trabajo encaminado en esta dirección sería el de Fernández Gordillo (2011), puesto que el de Guzmán Pérez (2014) es más bien un artículo de divulgación y los textos de Bürki (2014) y Fernández Gordillo (2010) estudian el Vocabulario de García Icazbalceta contrastándolo con obras de sus coetáneos². Parece que es precisamente Fernández Gordillo la investigadora que siente la mayor necesidad de cubrir las carencias de conocimiento sobre el Vocabulario, ya que más tarde ha vuelto a él otra vez para analizar las citas que contenía (Fernández Gordillo 2014).

En cuanto a otros estudiosos que mencionan el Vocabulario de García Icazbalceta en sus textos, Alvar Ezquerra (1996-97) se ha limitado a reconocer su valor para la historiografía de la lexicografía dialectal del español, mientras que otros auto-

* Este trabajo se inscribe dentro del proyecto Corpus diacrónico para el estudio de las actitudes lingüisticas en América y España en los siglos XVIII y XIX (FFI2016-76874-P), concedido por el Ministerio de Economía y Competitividad del Gobierno de España, y cuenta asimismo con el apoyo de la Facultad de Filosofía y Letras de la Universidad Masaryk.

${ }^{1}$ Como apunta acertadamente CHávez Fajardo (2015, p. 105), "urge la necesidad de iniciar un estudio monográfico de Vocabulario de mexicanismos comprobado con ejemplos y comparado con los de otros países hispano-americanos de García Icazbalceta, [ya] que podría traer interesantes informaciones respecto al tratamiento de la norma dentro de los procesos estandarizadores en el español hablado en América”.

${ }^{2}$ En el artículo de BÜRKI (2014) se presta principal atención a la obra de Darío Rubio, La anarquía del lenguaje en la América española, de 1925, y, por tanto, el papel del Vocabulario de García Icazbalceta es allí necesariamente secundario; el artículo de FERnández Gordillo (2010) es un estudio comparativo entre el Diccionario de mejicanimos de Félix Ramos i Duarte, de 1895, y el Vocabulario de García Icazbalceta. La investigadora contextualiza muy bien ambos diccionarios, pero probablemente por motivos de extensión se vio obligada a dejar fuera información más detallada sobre la macroestructura y la microestructura de ambas obras. 
res (León-Portilla 1981 y Martínez Baracs 2001 para los mexicanismos; Navarro Carrasco 2000 y 2001, Rojas 2011 o Chávez Fajardo 2015 para otros americanismos, entre otras posibles referencias) han tomado al lexicógrafo mexicano simplemente como una autoridad de referencia en el uso del léxico de dicha variedad durante su época y extrapolado sus observaciones, a veces, hasta la actualidad, sin profundizar más al respecto.

Es claro que en el presente estudio no podemos analizar la obra en toda su complejidad. Por tanto, esta vez nos limitaremos a examinar el valor sociolingüístico del Vocabulario, en concreto a las actitudes lingüísticas que expresaba el autor en sus páginas cuando hablaba de los usos -recomendables y no tan recomendables- del léxico de los hablantes del español mexicano en la segunda mitad del siglo XIX. En el estudio seguiremos principalmente el modelo de actitudes positivas y negativas de López Morales (1991), tomando también en consideración, por supuesto, postulados de otros autores (Moreno Fernández 2009; Blas Arroyo 2004; Milroy 2014; Langer \& Nesse 2014).

\section{El Vocabulario de mejicanismos en CONTEXTO}

El Vocabulario de García Icazbalceta quedó inconcluso, por lo que sólo llega hasta la letra G del alfabeto. Santamaría decidió trasvasarlo completo en su propio Diccionario de mejicanismos (2000 [1959]) -probablemente como reconocimiento a su calidad-, indicando con una cruz los artículos que provenían de allí. No obstante, el primer especialista que se dio cuenta del valor de la obra para la lexicografía diferencial del español fue Toro y Gisbert, al afirmar que "es esta la obra más metódica de las de su clase" (s.f., p. 199).

Ahora bien, a pesar de que el Vocabulario de García Icazbalceta se publicó en una época en que empezaron a salir a la luz los primeros diccionarios diferenciales del español de América, no es simplemente uno más de ellos. Aunque es probable que en buena medida haya compartido características con los demás diccionarios contrastivos, es decir, obras nacidas de una inspiración patriótica (cf. Huisa Téllez 2014) -que procuraba el buen uso de la lengua, pero vislumbraba el posible peligro de diferenciación de las variedades del español, la cual podría en un futuro más o menos lejano menoscabar la inteligibilidad mutua (tomando como ejemplo el latín y la formación de 
las lenguas románicas)-, creemos que difiere de ellos en varios aspectos, tanto desde el punto de vista de su macroestructura como de la microestructura.

Sobre todo, hay que destacar que no se trata de un diccionario correctivo en su totalidad, es decir, no está concebido como una colección de barbarismos locales cuyo uso debería evitarse, como fue, por ejemplo, el caso de su coetáneo Félix Ramos i Duarte, quien advertía que la principal motivación para recopilar su Diccionario de mejicanismos fue "reunir cuantas locuciones i frases viciosas hemos oído en el vulgo i leído en los periódicos, libros impresos (¡hasta en los diccionarios!) discursos, etc., ... no con el fin de señalar una falta, sino con el de corregirla i evitar que siga difundiéndose" (1895, p. 5). Otro ejemplo de parecida índole fue, entre otros posibles candidatos, el Diccionario de barbarismos y provincialismos de Costa Rica de Carlos Gagini (1893), que recogió entre sus páginas neologismos locales, "voces castizas empleadas en acepciones impropias", vulgarismos fonéticos y morfosintácticos, etc., que según la opinión del autor "contribuyen sobre modo á romper la unidad del idioma común de nuestras Repúblicas, preparando la formación de dialectos y dificultando el comercio de ideas" (1893, p. ii). A diferencia de estos y otros autores, García Icazbalceta estaba convencido de la importancia y del valor de los regionalismos en las variedades del español en general, y en la mexicana en particular (1899, p. xiii), cuando escribió:

¿Por qué, pues, hemos de calificar rotundamente de disparate cuanto se usa en América, sólo porque no lo hallamos en el Diccionario? Esos mal llamados disparates ¿no son á menudo útiles, expresivos y aun necesarios? ¿No suelen ser más conformes á la etimología, á la recta derivación ó á la índole de la lengua? Deséchese enhorabuena, con ilustrado criterio, lo superfluo, lo absurdo, lo contrario á las reglas filológicas; pero no llevemos todo abarrisco, por un ciego purismo ${ }^{3}$, ni privemos á la lengua de sus medios naturales para enriquecerse $e^{4}$.

3 Como comentan Langer y Nesse, el purismo nunca ha sido problema lingüístico de comunicación, sino más bien una preocupación social relacionada con la imagen de distinción de una lengua: "Concerns about linguistic purity are therefore separate from any real problems affecting communication: they are simply... sociological concerns related to the perceived status of «distinguished» languages... Perception of unity plays a crucial part in the historiography -both academic and lay- of nations" (2014, p. 616).

${ }^{4}$ Es preciso recordar que la preocupación por la unidad de la lengua que sentían los lexicógrafos hispanoamericanos a finales del siglo xix y 
Esta conciencia del valor del léxico regional hispanoamericano y de su importancia para el sentimiento identitario (o "patriótico", como decían los autores de finales del siglo xix y comienzos del xx) nació a partir de una actitud pluricéntrica que adoptaron los intelectuales hispanoamericanos cuando empezaron a observar los elementos diferenciales desde otra perspectiva, es decir, ya no como aberraciones que iban en contra del uso modélico del español (que había sido, y para muchos seguía siendo, el español peninsular, necesariamente idealizado), sino como productos de normas implícitas nacionales y regionales distintas (Torrejón 1991, apud Bürki 2014, p. 199). Sus colaboraciones con la RAE tenían sobre todo el fin de reivindicar una presencia más amplia del léxico hispanoamericano en las páginas del Diccionario académico. Afirma Fernández Gordillo (2010, pp. 117-118) que García Icazbalceta percibía la obra académica como un repertorio que "presenta, sin marca restrictiva geográfica, los vocablos, locuciones, frases y acepciones comunes a todos los hispanohablantes y correctos". Su interés por su variedad del español no era sólo nacionalista, sino eminentemente filológico, y estaba convencido de que su español mexicano era en principio tan correcto como el peninsular (Fernández Gordillo 2010, p. 119).

De allí se desprende que la importancia del Vocabulario de García Icazbalceta se halla precisamente en el hecho de haber elegido como elemento de contraste el español mexicano y no el estándar literario peninsular, como lo hicieron varios de sus predecesores y coetáneos. Como afirma Bürki, "dicha comparación contrastiva se realiza dentro de la igualdad jerárquica que éstas [las variedades del español] tienen, otorgándoles a

comienzos del xx estaba enmarcada en un afán bastante contradictorio entre el purismo, por una parte, y entre el nacionalismo o patriotismo, por otra, y que se explicaría por la procedencia criolla de las clases media y media alta de sus autores. Huisa Téllez (2014, p. 145) advierte que "si asumimos que los primeros lexicógrafos pertenecen a la élite cultural y económica de la sociedad postindependentista -en concreto, los criollos que heredan la administración colonial y el poder coercitivo-, está claro que los modelos que repetirán y difundirán a través de sus obras estarán claramente marcados por un sesgo ideológico propicio para ella”. Este hecho más tarde llevaría a la fundación de las academias americanas de la lengua correspondientes de la española y perpetuaría una posición de dependencia que varios autores han llamado "colonialismo lingüístico", que en la lexicografía hispanoamericana se manifiesta en la continua publicación de repertorios de -ismos hasta hoy día. Cf. SEnz 2011; LARA 2011; Zimmermann 2003 y 2012. 
todas las variedades el mismo valor lingüístico" (2014, p. 206). Es cierto que podemos encontrar en el Vocabulario de García Icazbalceta todos los tipos de justificaciones que yacen en el fondo de los diccionarios diferenciales del léxico hispanoamericano de la época, como: 1) misión pedagógica ("desterrar el barbarismo"), 2) servir de suplemento al Diccionario académico y 3) registrar la variedad, según la tipología de Bachmann (2007, apud Bürki 2014, p. 211); pero lo novedoso en su caso es la apuesta decidida a mirar el (buen) uso del español a través del prisma del español mexicano sin ningún complejo de inferioridad frente al peninsular. En otras palabras, el español mexicano tendría, a ojos de García Icazbalceta, el mismo prestigio que el peninsular ${ }^{5}$.

En lo que se refiere a la génesis del Vocabulario de García Icazbalceta, hay que decir que éste tiene su origen en un encargo de la RAE a la Academia mexicana de sus revisiones al DRAE1869 con el propósito de tenerlas en cuenta para la siguiente edición del Diccionario académico, que sería la correspondiente al DRAE-1884. García Icazbalceta, uno de los miembros fundadores de la Academia mexicana y su presidente desde el 1883, empezó a escribir con este motivo una colección de "Provincialismos mexicanos", que finalmente llegó a precisar de unas mil trescientas papeletas que sugerían enmiendas y adiciones a vocablos generales, ya incluidos en el DRAE, pero también mexicanismos, es decir, voces privativas de esta variedad del español. De todas las propuestas, la RAE aceptó poco más de la mitad, sin explicar nunca a la Academia mexicana su criterio de selección. García Icazbalceta especulaba que la RAE había dado preferencia a voces y acepciones que tenían sustento en documentación del español peninsular, pero parece más bien un intento de convencerse a sí mismo, "para que no pensemos haber trabajado en vano" (1899, p. v). Hay que apreciar la actitud positiva y conciliadora con la que tomó el académico mexicano el desplante de la RAE.

Para dar a conocer la labor emprendida, García Icazbalceta publicó en el año 1886 en el tercer tomo de las Memorias de la Academia Mexicana un amplio ensayo titulado "Provincialismos mexicanos" (pp. 170-190), en el que explicó en qué había consistido el trabajo encargado por la RAE a la Academia mexica-

${ }^{5}$ Como escribe Milroy (2014, p. 572): "Prestige, however, is a social, not a linguistic, concept". 
na y en el que defendió su opinión acerca del pluricentrismo del español y de la igualdad de las variedades de la lengua. El texto luego fue publicado con el mismo título como prólogo de su Vocabulario póstumo ${ }^{6}$. En este tomo también se recogieron los listados de "Artículos de la letra $A$, admitidos en el Diccionario, en todo ó en parte" (pp. 191-199), "Los artículos de las letras $B$ y $C$..." (pp. 296-301) y "Los artículos de las letras $C H$ á Z...” (pp. 426-433).

Las papeletas, tanto las admitidas como las desestimadas por la RAE, sirvieron a García Icazbalceta como punto de partida para su propio diccionario que, desgraciadamente, sólo logró preparar hasta la letra $G$. El autor no detalló en ningún momento cómo seleccionaba los lemas, pero por la estructura de los artículos y las citas deducimos que se apoyaba sistemáticamente en fuentes primarias mexicanas. Fernández Gordillo (2014) ha llevado a cabo un estudio detallado de las referencias bibliográficas o simplemente de los apellidos de autores presentes en el Vocabulario, y comenta:

he contabilizado más de trescientas referencias distintas que comprenden obras lexicográficas, textos especializados, textos periodísticos, documentos históricos y textos literarios. Además hay otras autoridades extraídas de textos no precisados como: "de un escritor mexicano contemporáneo", "tomado de un periódico" y, como es obvio, las coplas populares de autores desconocidos (2014, p. 529).

Los artículos no tienen una estructura uniforme, y más que de "artículos lexicográficos" cabría hablar de "microestudio"7 sobre el uso de determinadas voces mexicanas en relación con los usos documentados en fuentes contrastivas de otras variedades del español en América y con las indicaciones que ofrecía la edición del DRAE vigente, entonces la de 1884. El autor incluía la información gramatical, indicaciones sobre el nivel de uso, definición (frecuentemente enciclopédica); informaba sobre la vigencia de uso de las voces y de sus acepciones en otras variedades del español, tal como aparecían en los diccionarios contrastivos que manejaba, e incluía a la vez varios ejemplos procedentes de fuentes textuales mexicanas.

${ }^{6}$ Nuestras citas provienen de allí.

7 Según apunta Fernández Gordillo (2011, p. 108), García Icazbalceta mismo lo llamaba "método de Baralt". 
En otras ocasiones, el lexicógrafo entraba en polémica con las definiciones académicas aduciendo pruebas de usos mexicanos y latinoamericanos que contradecían las indicaciones en el Diccionario académico vigente. Los siguientes dos artículos serían buenos ejemplos para ilustrar la estructura que éstos solían tener en el Vocabulario:

1. *Acocote. (Del mex. acocotli). m. Calabaza larga, agujereada por ambos extremos, que se usa para extraer, por succión, el aguamiel del maguey. "He visto, por desgracia, que algunos han soltado el acocote para tomar el cáliz" (Pensador, Periquillo, tom. I, cap. 9, p. 107). Rivodó (p. 31) censura á la Academia por haber dado lugar á este terminacho en el Diccionario.

2. *Acojinar. a. Revestir los muebles, ú otras cosas, con un acolchado grueso, para hacerlos más cómodos. La Academia, como pr. de Méj., le da el equivalente acolchar. Entre nosotros, á lo menos, el ACOJINADO es mucho más grueso que el acolchado.

Ponderado el contexto histórico-social y de ideas lingüísticas en el que nació la obra, a continuación proseguiremos a la parte central de nuestro trabajo, es decir, al estudio de actitudes lingüísticas que se perciben en la obra.

\section{Actitudes lingüísticas en el VocabUlaRio de MejICANISMOS}

En lo que se refiere al valor social de los diccionarios, sostenemos la opinión de Lara (1997) de que son obras determinadas por la realidad de la época en la que nacen, y el Vocabulario de García Icazbalceta no es en este aspecto ninguna excepción. Puesto que se trata de un texto con decidida proyección tanto "nacional", o mexicana, como "internacional", es decir, pensado para autores con semejantes inquietudes en otras naciones hispanohablantes -hablantes de otras variedades del españoly, sobre todo, con proyección hacia la RAE y su Diccionario, no sorprende que encontremos a lo largo del repertorio del académico mexicano muchas opiniones sobre el uso de la lengua en dicha variedad del español tal como se reflejaba en los textos que le sirvieron de base para su propia obra lexicográfica. Estas opiniones sobre el uso de la lengua en un contexto social determinado reciben en la sociolingüística el nombre de actitudes lingüisticas y se definen como 
manifestación de una actitud social de los individuos, distinguida por centrarse y referirse específicamente tanto a la lengua como al uso que de ella se hace en la sociedad, y al hablar de la "lengua" incluimos cualquier tipo de variedad lingüística: actitud hacia estilos diferentes, sociolectos diferentes, dialectos diferentes o lenguas naturales diferentes (Moreno Fernández 2009, pp. 177-178).

Al recopilar las voces, el autor transmitía al público una determinada manera de cómo él (y probablemente también las personas del mismo entorno social) percibía el uso que se hacía del español en distintos estratos de la sociedad mexicana de aquel entonces y, mediante sus observaciones en las páginas del Vocabulario, invitaba a sus lectores a compartir su perspectiva del mundo y su actitud hacia él. Frecuentemente, su actitud positiva o negativa hacia usos o fenómenos lingüísticos concretos se veía determinada por lo que hoy denominaríamos variables lingüisticas, como el sexo, la edad y el nivel sociocultural y socioeconómico de las clases sociales que los manejaban. Moreno Fernández apunta:

Las actitudes lingüísticas son reflejo de unas actitudes psicosociales; de hecho son actitudes psicosociales. Si, como hemos comentado, las lenguas tienen un significado o unas connotaciones sociales, es natural que sean apreciadas y evaluadas de acuerdo con los estatus o las características sociales de sus usuarios. Por eso no resulta fácil delimitar dónde comienza la actitud hacia una variedad lingüística y dónde termina la actitud hacia el grupo social o el usuario de esa variedad (2009, p. 179).

Tales actitudes psicosociales de ciertos grupos y sus usos lingüísticos hacia otros son por supuesto subjetivas y "obedecen principalmente a los desequilibrios de poder entre unos grupos y otros", según advierte Blas Arroyo (2004, p. 324), puesto que "no son diferencias lingüísticas ni estéticas las que se encuentran en el origen de las actitudes lingüísticas, sino estereotipos y prejuicios relacionados con las personas que hablan determinadas lenguas o variedades" (p. 325). La "corrección” y la "incorrección" de los modos de hablar no se deben a criterios lingüísticos, sino sociales, toda vez que, como observan Langer y Nesse (2014, p. 611), "it is rather a social commentary on the (perceived) declining standards - linguistic, moral and educational of modern society". 
En lo que se refiere al modelo metodológico que vamos a utilizar, hemos acudido al de López Morales (1991) que, según nuestra opinión y como explicaremos en seguida, es el más apto para una investigación cualitativa de corte histórico, basada en una fuente escrita en que las actitudes que se ven son las que García Icazbalceta consciente o inconscientemente introdujo allí; las condiciones de la selección de datos no las impone el investigador armado con cuestionarios sofisticados, sino el autor que nos legó lo que a él le pareció pertinente; nuestra tarea, por tanto, es interpretar la información como mejor podamos.

A diferencia de otros autores, López Morales separa las creencias de las actitudes. Como explica el investigador:

Para nosotros la actitud está dominada por un solo rasgo: el conativo, en contra de modelos más elaborados, que hablan de varios. A diferencia de casi todos y a la semejanza de Fishbein, separo de la actitud el concepto de creencia que es, junto al "saber" proporcionado por la conciencia lingüística, el que las produce. Las actitudes sólo pueden ser positivas, de aceptación, o negativas, de rechazo; una actitud neutra es imposible de imaginar (pensando en su naturaleza conativa): se trata más bien de ausencia de actitud (1991, pp. 234-235).

En lo que se refiere a las creencias, continúa explicando que éstas "pueden estar basadas en la realidad..., pero en gran medida no aparecen motivadas empíricamente" (1991, pp. 235236). Estamos más bien ante comentarios y discursos metalingüísticos que reflejan los gustos sobre los usos del lenguaje de parte de determinados estamentos sociales (Langer \& Nesse 2014, p. 611).

Ahora bien, como los diccionarios de lengua (incluso los contrastivos) tienen función pedagógica, es decir, orientan al usuario sobre un buen o mal uso de la lengua (Anglada 1991), las actitudes que contienen cumplen con la función conativa, es decir, intentan dirigir la conducta de sus lectores o usuarios y pretenden provocar en ellos la aceptación o el rechazo de determinados fenómenos lingüísticos según criterios de corrección que, de hecho, no son lingüísticos, sino sociales. Como observan Langer y Nesse, "dictionaries are not neutrally compiled lists of all existing words but, rather, subjective accounts of what ought to be part of a particular language" 
(2014, p. 613), descripción de la que no escapa el Vocabulario de García Icazbalceta, puesto que, como advierte Fernández Gordillo: "Algunas calificaciones de Icazbalceta obedecen más a lo que se podría caracterizar como ideología moral de los estratos sociales cultural y económicamente medios y altos" (2011, p. 120).

En síntesis, entendemos en este estudio por actitudes lingüisticas observaciones expresamente formuladas sobre usos lingüísticos que, según la opinión de García Icazbalceta como representante de la clase media o media alta culta de la sociedad mexicana de la segunda mitad del siglo xıx:

a) formarían parte de un comportamiento lingüístico socialmente aceptable y en general aceptado en el ámbito del español mexicano de la época dentro de su propia clase social; en este caso se trataría de actitudes positivas, y la orientación que García Icazbalceta daba a sus lectores fue que no sólo pertenecían al español mexicano en su uso culto, sino que tenían todo el derecho de encontrar cabida en el inventario general de la lengua española, que sería el Diccionario académico;

b) comprenderían, por lo demás, comportamientos lingüísticos ferozmente censurados desde la perspectiva de la clase social que él mismo personificaba; en este segundo caso estaríamos ante actitudes negativas, y el mensaje que transmitía García Icazbalceta a su público acerca de aquellas voces y usos lingüísticos decía que eran incompatibles con lo que hoy denominaríamos habla culta. Por tanto, quien en aquel entonces los profiriera quedaría descalificado del grupo de buenos hablantes del español mexicano (con el que García Icazbalceta seguramente se identificaba).

Estamos, pues, ante indicaciones sobre qué recursos lingüísticos son aceptables y cuáles no lo son y por qué. Son orientaciones positivas o negativas -no se contemplan actitudes neutras, de ahí que nos inclinemos por el modelo de López Morales (1991)-, y están dictadas desde la perspectiva de estratos sociales con mayor poder e influencia en la sociedad mexicana de aquella época.

A continuación, observaremos con detalle, según los criterios que acabamos de esbozar, qué tipos de actitudes lingüísticas podemos encontrar en las páginas del Vocabulario de García Icazbalceta y a qué niveles y ámbitos de uso del español mexicano se refieren en concreto. 


\section{Actitudes positivas}

Si interpretamos el Vocabulario de García Icazbalceta en el contexto de otros diccionarios hispanoamericanos diferenciales de la época, notamos que las actitudes positivas hacia la modalidad mexicana del español estaban en el fondo mismo de la obra como tal. El autor estaba convencido, como hemos visto más arriba, de que la variación regional de la lengua era un hecho natural y no entraba en conflicto con el uso "correcto" del español en general. En este sentido cabrían aquí, en principio, todas las voces que a primera vista se muestran como neutras en el Vocabulario.

En algunos casos, el autor se sentía obligado a explicitar que eran voces con acepciones mexicanas propias, pero correctas y neutras dentro del español mexicano, como serían los casos, por ejemplo, de banca, barra, barrial, bazar, buscavidas o capaz:

3. † Banca. f. "Asiento de madera sin respaldo, y á modo de una mesilla baja", dice el Diccionario; y según el mismo, Banco es "asiento de madera, por lo común, con respaldo ó sin él, en que pueden sentarse á un tiempo algunas personas.” Acá trocamos estos términos.

4. † Barra. f. "Rollo de oro, plata ú otro metal sin labrar." (Dicc.) Entre nosotros la barra de plata pura, plata mixta ú oro tiene la forma de una artesa, y su peso legal máximo es de 135 marcos.

5. † Barrial. adj. Aplicado á la tierra gredosa ó arcillosa, no está aquí anticuado: también se usa como sustantivo. En el sentido de barrizal ó lodazal no se oye nunca.

6. Bazar. m. "Tienda en que se venden productos de varias industrias, comúnmente á precios fijos." (Dicc.) Aquí se conoce por BAZAR la tienda en que se compran y venden objetos de todas clases, casi siempre usados.

7. † Buscavidas. f. pl. Además de las acepciones que le da el Diccionario, tiene aquí la de persona que anda acusando á otros para procurarles algún mal.

8. $\uparrow$ Capaz. adj. Singular uso, y continuo, hacemos de esta palabra, en el sentido general de posible ó probable.

En otras ocasiones se trataría de variantes formales -con variación morfológica, por ejemplo, de género, o con variación fonética- consideradas incorrectas en otras variedades o según la gramática académica, pero avaladas por el uso neutro 
en México y, por lo tanto, aceptables en el uso culto o "correcto", según la terminología del autor:

9. Correita. f. dim. reg. de correa, muy de acuerdo con nuestra afición á los diminutivos en ito... Algunos dicen correyita, y no es de condenarse, puesto que el Diccionario da correyuela, y Salvá correya como anticuado.

10. † Azúcar. En México no ambiguo, sino siempre femenino, en singular y plural.

11. † Azucarera. f. Azucarero: vaso para poner el azúcar en la mesa. Siempre le damos el género femenino.

12. Cabrestear. n. Úsase en México, con rara excepción, en vez de cabestrear. Salvá trae Cabrestear, como anticuado.

13. Cabrestero. $\mathrm{m}$. Cabestrero, el que hace y el que vende cabrestos (ó sea cabestros).

14. Cabrestro. m. Es tan general en México el uso de esta forma, que causa extrañeza oír la correcta cabestro.

El siguiente grupo de mexicanismos serían los mal llamados arcaísmos, es decir, voces que habían caído en desuso en otras variedades del español, sobre todo en el peninsular, pero que seguían con plena vigencia en el mexicano. Un ejemplo ya lo hemos visto en el caso de cabrestear, que Salvá, autor español, marcó como anticuado en su diccionario. En los casos de otros arcaísmos, García Icazbalceta argumentaba apasionadamente que las variantes mexicanas correspondían, de hecho, a formas más cercanas a su etimología o a las más antiguas, por lo que las juzgaba más exactas.

15. Arfil. m. Pieza del juego del ajedrez. Así decimos aquí siempre, y no alfil, única forma que registra el Diccionario, y es más conforme á la etimología.

16. Ciénega. f. ¡Cuántas veces hemos oído censurar á los que dicen ó escriben ciénega, como si hubiesen soltado un enorme disparate! Sin embargo, habrán usado, cuando más, de un arcaísmo tan generalizado entre nosotros, que la gente se reiría del que dijese ciénaga.

17. Desgavilado, da. adj. Desvaído, desairado, falto de gracia y de vigor. Cuando usamos de este adjetivo, que no está en el Diccionario, no hacemos más que seguir á notables escritores andaluces.

El último grupo de voces con evaluación de uso positiva comprende los llamados neologismos necesarios. Como hemos 
visto más arriba, García Icazbalceta no era nada purista y no dudaba en dar la bienvenida a voces de reciente formación si creía que eran útiles, incluso cuando se trataba de galicismos, censurados sin piedad por sus coetáneos:

18. Editar. (Del lat. edere). a. Sacar á la luz una obra ajena, y cuidar de su impresión... Baralt, que en todas partes veía galicismos, la condena, por ser traducción ó calco del verbo francés éditer. Si hubiera subido un poco más, habría encontrado que ambas traen su origen del latín... Mas como es útil y de buen origen, acabará por tomar asiento en el Diccionario.

19. † Editorial. m. Artículo de fondo, en los periódicos... Palabra usadísima y útil.

20. Extorsionar. a. Causar extorsión. Verbo de bastante uso por acá; no mal formado y útil.

Por último, hemos incluido dos voces en cuyos casos la actitud positiva del autor obedecía a otros criterios: en el de desvestirse, al reconocimiento de su mayor precisión semántica en combinación con un sentimiento de pudor para evitar un doble sentido; en el de caquinos, a la preferencia del latinismo frente a la imagen de mandíbula batiente, que tal vez le desagradaba.

21. Desvestirse. pr. Este verbo no aparece en el Diccionario, y sería conveniente admitirle para evitar lo indecoroso de ciertas frases en que se emplea desnudará falta de otro. Desnudar, desnudarse, debieran servir para expresar que se quita todo vestido; y Desvestirse para dar á entender que se quita solamente el vestido exterior... Desvestirse comienza á usarse de nuevo, y claro es que lo aplaudimos.

22. Caquinos. (Del latín cachinnus.) m. pl. Carcajadas: reírá CAQUINos, reír á carcajadas. En caso de necesidad prefiero mil veces la palabra latina á la antipática frase reír á mandíbula batiente, que usan algunos revisteros.

Aunque hemos argumentado que las actitudes positivas habrían estado al fondo de la obra como tal, es cierto que al fin y al cabo nos encontramos ante un diccionario diferencial $y$, por tanto, no extraña que contenga un elevado número de voces cuyo uso el autor censuraba, no por ser mexicanismos, sino por el hecho de considerarlas incorrectas, siempre con algún fundamento. 
Actitudes negativas

Ahora bien, hay que precisar que no siempre es tan clara la diferencia entre una nota que simplemente informaba sobre el uso de determinada palabra y una nota que expresaba las actitudes lingüísticas negativas de García Icazbalceta hacia cierto uso que, por una razón u otra, consideraba censurable. Creemos que en los ejemplos de desborrar, desfrutary escalfar se trataría más bien de marcas de uso; completar y desaguar son bastante ambiguos, mientras que en los ejemplos de fiero y fregar ya se ven las actitudes del autor hacia su uso cuando las tenía por "disparates" y "soeces e indecentes".

23. † Desborrar. a. Lo mismo que borrar. Le usa el vulgo.

24. $\uparrow$ Desfrutar. a. El Diccionario le da como anticuado por DIsFRUTAR... Corre todavía mucho entre el vulgo.

25. $\uparrow$ Escalfar. a. Descalfar; separar parte de una cosa, en especial de dinero, propio ó ajeno. Usado por el vulgo.

26. † Completar. a. vulg. Igualar á otro en fuerza ó en otras cualidades, físicas ó morales. Úsase más con negación; es del estilo vulgar y aun bajo.

27. $†$ Desaguar. n. El Diccionario dice: "r. fig. Exonerarse por vómito ó cámara, ó por ambas vías". Acá se toma solamente por orinar. Es de poco uso y no entre gente culta.

28. $\uparrow$ Fiero. a. adj. FiERo por feo se encuentra en el Diccionario, lo mismo que en el de Autoridades y en el de Terreros. Aquí sólo le usa la gente vulgar, pues se tiene por disparate.

29. † Fregar. a. Por molestar, fastidiar, perjudicar, es, como amo$\operatorname{lar}(\mathrm{V}$.$) , una palabra baja, soez e indecente, que jamás debie-$ ra oírse, en boca de persona bien educada.

Las actitudes lingüísticas negativas de García Icazbalceta estaban orientadas tanto hacia los usos orales como hacia los escritos del área del español en México que el autor consideraba desprestigiados y no recomendables. En el caso de los usos orales, se trataba de expresiones propias de los estratos más bajos de la sociedad mexicana. Si iban acompañadas con citas, provenían en general de fuentes literarias que imitaban en los diálogos la manera de hablar de las clases desfavorecidas. En el caso de los usos escritos, arremetía contra las formas diafásica y diastráticamente marcadas que encontraba en fuentes escritas de carácter no literario, contra galicismos y otros extranjerismos que no estimaba "útiles" y contra 
otros usos que interpretaba como inadecuados para el habla culta y "correcta" 8 .

En lo que se refiere a los usos orales, censuraba algunos de la variación fonética (arcina, catredal, constumbre o dentrífico) -mientras que aprobaba otros; véase supra ciénega-, casos que se desaprobaban también en otras variedades. En sus dictámenes negativos, García Icazbalceta a menudo coincidía con Cuervo, a quien citaba in extenso.

30. Arcina. f. Corrupción intolerable, pero muy generalizada, de Hacina ( $1^{\mathrm{a}}$ acep.), montón de gavillas de trigo, cebada \&c., y también de paja.

31. Catredal. f. Forma anticuada ó metátesis de Catedral, que el vulgo retiene todavía y es ya un barbarismo.

32. Constumbre. f. Costumbre. Forma viciosa, muy general entre el pueblo y algo más arriba. Salvá la trae como anticuada... Añadiremos que es bastante común dar á CostumbRe el género masculino; pero es un disparate. Se vicia igualmente el verbo.

33. Dentrífico, ca. adj... Verdad es que la palabra viene de dens y fricare; pero puede suceder que el disparate no sea más que una metátesis introducida por el uso de suavizar la pronunciación, echando á rodar la etimología.

También encontramos casos de variantes morfológicas mal consideradas, como ésta del empleo pronominal del verbo enfermarse:

34. † Enfermarse. pr. Censúrase el empleo de este verbo en la forma pronominal, que es aquí la corriente, en lugar de la neutra.

Sin embargo, el grupo más numeroso de palabras y acepciones censuradas dentro del ámbito popular correspondía a aquellas que García Icazbalceta consideraba incompatibles con la variación de registro aceptable para él en el marco del habla culta mexicana. Estas voces las caracterizaba generalmente como "disparates", "indecentes", "bajas", "que nunca usa la gente educada" o hasta "antipáticas". Incluso estaba dispuesto a festejar la muerte léxica de una voz que aborrecía probablemente por motivos de pudor ( chichi), en tanto que recomendaba que otra se dejara caer en el olvido (ciscarse).

8 Se trataría de interferencias con lenguas y variedades "no deseadas" (LANGER \& Nesse 2014, pp. 621-622). 
35. $\uparrow$ Amolar. a. Fastidiar, molestar mucho, causar grave perjuicio. Úsase también como pronominal. Es voz baja, y aun indecente, de que nunca usa la gente bien educada.

36. † Arrempujar. a. No es anticuado aquí por rempujar, pero la gente educada no usa ni de uno ni de otro verbo, sino que siempre dice empujar.

37. Arrempujón. m. Rempujón. Ni uno ni otro se oye en boca de gente bien educada; sino empujón ó empellón. Aquéllos son propios del vulgo.

38. Carcajear. n. y pr. Reírse á carcajadas. Verbo antipático que solamente el vulgo usa.

39. † Ciscarse. pr. vulg. Avergonzarse, correrse. He aquí un verbo peliagudo por la sucia acepción que tiene en castellano. Mas hay que resolverse á estamparle, porque aquí se usa, aunque no entre la gente educada, y no despierta idea indecorosa. No sería malo, con todo, dejarle caer en olvido, para mayor seguridad, habiendo, como hay, otros sin mácula de que echar mano.

40. $\uparrow$ Condenado, da. adj. Calificativo injurioso y detestable de que se usa y abusa tanto, que ha llegado á perder su siniestra significación de réprobo, y hasta se aplica á cosas inanimadas.

41. Chichi. (Del mex. chichi, mamar. Mol.) f. vulg. Pecho, teta, ubre... Por fortuna este feo vocablo casi ha desaparecido.

42. Chichigua ó Chichihua. f. Voz de idioma mexicano, muy usada antiguamente; pero inútil, pues tenemos la castellana nodri$z a$, que ha prevalecido y desterrado de la buena sociedad á la otra.

43. Desapartar a. El vulgo usa este verbo como sinónimo de apartar, cuando en realidad, por la añadidura de la preposición inseparable des, viene á significar lo contrario. Pero este disparate es antiguo y no de nuestra cosecha, sino que vino del vulgo de España.

En lo que respecta a voces y acepciones que el lexicógrafo juzgaba inadecuadas para la producción escrita, una buena parte de ellas correspondía a neologismos, léxicos y semánticos, o a usos todavía no lexicalizados. También aquí solía valorarlos como "innecesarios", "intolerables y disparatados", como "abusos" o "disparates".

44. † Aproximativo, va. adj. En castellano es "lo que aproxima", según el Diccionario. En tal sentido creo que rara vez habrá necesidad del vocablo.

45. † Demasiadamente. adv. de cant. Equivale á demasiado, según el Diccionario, y se abusa igualmente de él, empleándose en vez de mucho, muy. 
46. † Demasiado. adv. de cant. Es intolerable el disparatado abuso que se hace del adverbio tomándole, convenga ó no, por muy, mucho, bastante, y no por excesivamente, más de lo debido, en demasía, que es su significación.

47. Dictaminar. n. Dar ó presentar dictamen... Este desgraciado verbo, lejos de haber entrado en el Diccionario, ha sido anatematizado expresamente dos veces en la Gramática de la Academia (1880)...

48. † Devolverse. pr. Por volverse-ME Devolví de la esquina- es un disparate que anda por aquí y en otras partes de América.

En algunas ocasiones, apuntaba errores en la denotación (dintel), mientras que en otras censuraba las voces por ser ocasionalismos (cariacontecer, ejecutista). También a éstas las tildaba de "inútiles" y "desatinadas".

49. $\uparrow$ Dintel m. No faltan entre nosotros ejemplos del desatinado uso de DINTEL por umbral.

50. Cariacontecer. a. Poner cariacontecido á alguno. Jamás he oído este verbo, ni le he hallado escrito más de una sola vez. El ejemplo no es de imitarse.

51. Ejecutista m. y f. Voz moderna inútil y poco usada: el que toca con perfección un instrumento.

Por último, cabrían en este apartado voces que en principio pertenecerían a la variación fonética del habla popular. No obstante, como el autor las recogió en fuentes escritas no literarias, las incluimos aquí:

52. Estantino. m. vulg. Ano: probablemente corrupción de intestino... No traería yo á colación esta palabra vulgar y aun baja, si no fuera porque anda impresa, y porque me la encuentro en el Ecuador.

53. Exprimentar. a. Experimentar. Disparate que corre entre el vulgo, y que sale aquí á la vergüenza porque se atreve á andar en letras de molde.

Un tópico en los repertorios léxicos hispánicos del siglo xıx a ambos lados del Atlántico eran los extranjerismos, sobre todo los galicismos, que la mayoría de los lexicógrafos y preceptistas veía como un serio peligro para el buen uso de la lengua. También García Icazbalceta recogió en el Vocabulario varios galicismos cuyo uso censuraba por considerarlos "inútiles", "disparatados", en fin, por representar un "virus galicano 
que infestaba" el buen uso del español. En el diccionario recogió también algunos anglicismos; unos los aceptaba por necesarios (cold-cream), pero rechazaba otros por "inútiles" (excéntrico).

54. $\uparrow$ Accidentado, da. Adj. Hablando de caminos, doblado, fragoso, quebrado \&c., y antiguamente agro. Es neologismo ó galicismo inútil y disparatado. Condénanle con justicia Baralt, Cuervo (§ 479), Rodríguez (p. 10); mas le defiende Rivodó (p. 146).

55. † Afectar. a. Apropiar, destinar una cosa ó algún uso. Tiénesele por galicismo reprobable... Úsanle también algunos en el sentido de tomar ó remedar una cosa la forma ó apariencia de otra: éste parece ser galicismo inútil.

56. † Cambiar es trocar una cosa por otra: supone un convenio entre dos personas, mediante el cual dos cosas mudan de dueño, de modo que la que antes fué propiedad del uno pasa á serlo del otro. Así pues, CAMBIAR de ropa quiere decir que A y $\mathrm{B}$ se quitan la que tienen puesta y la truecan, vistiéndose A la de B, y B la de A... Mudar es simplemente dejar una cosa y tomar otra... ¿Por qué no decir múdanse los tiempos, las circunstancias \&c., pues que la primera acepción de mudar es "dar ó tomar otro ser ó naturaleza, otro estado, figura, lugar" \&c? Lejos de eso, vamos desterrando á mudar y metiendo en todo á CAMBIAR, quepa ó no quepa. Es consecuencia del virus galicano que infesta hasta los últimos rincones de nuestra habla.

57. $\uparrow$ Concurrencia. f. Usado por competencia (y corre ya mucho por desgracia) me parece galicismo descomunal, por más que en negra hora se haya colado por las puertas del Diccionario, con la cual ha usurpado títulos que no le pertenecen.

58. † Excéntrico, ca. (Del inglés eccentric...) m. y f. neol. Extravagante, original, caprichoso. (ORTUZAR). Es inútil y debe desecharse.

Como hemos visto, no es fácil identificar un sistema en las actitudes negativas de García Icazbalceta. Por un lado, y como era de esperar, no veía con buenos ojos los galicismos y anglicismos, pero, por otro, no era un purista obcecado, y si creía que los extranjerismos podían ser útiles, los aceptaba sin problema. En lo que se refiere a otras voces y acepciones, allí su patrón de actitudes ya no se deduce fácilmente. Tendía a rechazar la variación fonética, pero no de manera sistemática. En el caso de palabras y acepciones diafásica y diastráticamente marcadas, muchas veces no está nada claro hasta qué punto era capaz de tolerarlas. No sorprende su rechazo hacia el léxico malsonante 
o con un posible doble sentido, pero no es posible determinar en qué momento los usos populares, siempre limitados en el habla culta, se volvían "disparates desatinados". Si tomamos en cuenta los ejemplos que aportaba, vemos que García Icazbalceta se mostraba relativamente tolerante cuando los usos provenían de la literatura popular o cuando ilustraban el habla popular en la literatura costumbrista. Pero si los usos populares figuraban en fuentes no literarias, sobre todo en textos periodísticos, los censuraba ferozmente, porque allí entraban ya en conflicto con el habla culta mexicana, es decir, con los usos habituales en registros neutros y formales (en su forma oral, pero sobre todo escrita), propios de hablantes que pertenecían a la misma clase social que él o que aspiraban a imitarlos ${ }^{9}$.

\section{Conclusiones}

Según hemos podido observar a lo largo del presente estudio, el Vocabulario de mejicanismos de Joaquín García Icazbalceta contiene un valioso material de estudio acerca del léxico del español mexicano en la segunda mitad del siglo xıx en su complejidad sociolingüística.

Aunque es un diccionario contrastivo y hasta cierto punto correctivo, es preciso advertir que para cualquier interpretación que se haga del léxico del Vocabulario es siempre necesario tener en cuenta que su contrastividad fue relativa y que las observaciones sobre usos correctos e incorrectos no tenían como referente el español peninsular o la RAE y su Diccionario, sino que se referían al uso culto o "correcto" en el marco del español mexicano entendido como una variedad regional autónoma del español. En este sentido, el Vocabulario, por muy performativo y artificial que fuera, formaría parte de un proceso de construcción de identidades nacionales, en este caso, de la identidad mexicana, y sería uno de los primeros símbolos de su manifestación historiográfica y sociolingüística.

Al comienzo de este estudio hemos citado a varios autores que han acudido al Vocabulario de García Icazbalceta como obra

${ }^{9}$ No tenemos el espacio aquí para entrar en detalles sobre relaciones entre las citas, las actitudes que expresan y la interpretación que de ellas tenía el lexicógrafo. Sería tema para otro trabajo. En cuanto a la información sobre las citas y fuentes que manejaba García Icazbalceta en el Vocabulario, véase FERNÁNDEZ GORDILLO 2014. 
de referencia y autoridad para avalar el uso de mexicanismos, o incluso americanismos, y hemos reproducido a la vez el llamamiento de Chávez Fajardo (2015) para que se emprenda un estudio monográfico sobre el diccionario. Todo ello apunta al hecho de una urgente necesidad de realizar su balance historiográfico, bien detallado y adecuadamente contextualizado. Hay toda una serie de cuestiones que deberían tratarse, como el análisis pormenorizado de su macroestructura y microestructura, su relación con obras de otros autores -coetáneos y posteriores- o su valor sociolingüístico, aquí reducido tan sólo a las actitudes lingüísticas. Algunas de estas cuestiones ya han sido atendidas (cf. Fernández Gordillo 2010, 2011 y 2014; Bürki 2014; Buzek 2019); no obstante, es preciso ofrecer una visión de conjunto, porque el Vocabulario no es solamente un diccionario diferencial, sino una obra con proyección interdisciplinar que encierra valioso material para la historia del léxico, aspectos sociolingüísticos, historiográficos y de política lingüística.

Tal vez sea mucho presuponer, pero estamos convencidos de que García Icazbalceta era consciente de que el español equivalía a una lengua pluricéntrica y de que el español mexicano tenía cualidades suficientes para enriquecer con su léxico privativo el ámbito de habla culta en general. La "mexicanidad" de su nomenclatura es la clave para que podamos entender adecuadamente las actitudes positivas y negativas que expresó el autor en las páginas de este diccionario inconcluso.

\section{REFERENCIAS}

Academia Mexicana de la Lengua 1886. Memorias de la Academia Mexicana, t. 3, Imprenta de Francisco Díaz de León, México, http://www.academia.org.mx/aml_static/memorias/tomo3/tomo3.html [consultado el 26 de junio de 2018].

Alvar EzQuerra, Manuel 1996-97. "Lexicografía dialectal”, Estudios de Lingüistica de la Universidad de Alicante, 11, pp. 79-108.

ANGLADA, Emília 1991. "Lexicografía, metalexicografía, diccionario, discurso”, Sintagma, 3, pp. 5-11.

Blas Arroyo, José Luis 2004. Sociolingüistica del español. Desarrollos y perspectivas en el estudio de la lengua española en contexto social, Cátedra, Madrid.

Bürki, YvetTe 2014. "Darío Rubio: ¿La anarquía del lenguaje en la América española? Hacia el reconocimiento del léxico americano y del mexicano en particular", Boletín Hispánico Helvético, 23, pp. 195-226.

Buzek, Ivo 2019. "El léxico argótico en el Vocabulario de mexicanismos de Joaquín García Icazbalceta”, Anuario de Estudios Filológicos, 42, pp. 23-42. 
Chávez Fajardo, Soledad 2015. "Memorias discursivas en producciones lexicográficas decimonónicas. Fuentes para la historiografía e historia de la lengua española”, Études Romanes de Brno, 36, 2, pp. 87-110.

Fernández Gordillo, Luz 2010. "Las obras representativas de la lexicografía diferencial de México en el contexto hispanoamericano y sus recepciones en el DRAE", en Metalexicografia variacional. Diccionarios de regionalismos y diccionarios de especialidad. Ed. Ignacio Ahumada, Universidad de Málaga, Málaga, pp. 107-128.

Fernández Gordillo, Luz 2011. "El Vocabulario de mexicanismos de Joaquín García Icazbalceta”, en De la lengua por sólo la extrañeza: estudios de lexicología, norma lingüistica, historia y literatura en homenaje a Luis Fernando Lara. Eds. María Eugenia Vázquez Laslop, Klaus Zimmermann y Francisco Segovia, El Colegio de México, México, t. 1, pp. 99-123.

FERNÁNDEz Gordillo, Luz 2014. "Autoridades y correspondencias en el Vocabulario de mexicanismos de Joaquín García Icazbalceta”, en Lenguas, estructuras y hablantes: estudios en homenaje a Thomas C. Smith Stark. Eds. Rebeca Barriga Villanueva y Esther Herrera Zendejas, El Colegio de México, México, t. 1, pp. 521-579.

Gagini, Carlos 1893. Diccionario de barbarismos y provincialismos de Costa Rica, Tipografía Nacional, San José.

García Icazbalceta, JoaQuín 1899. Vocabulario de mejicanismos comprobado con ejemplos y comparado con los de otros paises hispano-americanos, Tip. y Lit. "La Europea", México.

Guzmán Pérez, Vanesa 2014. "Un acercamiento a la labor de Joaquín García Icazbalceta en el Vocabulario de mexicanismos”, Calmécac, 17, pp. 14-18, https://issuu.com/uvp_puebla/docs/revista_calm_cac_17_uvp_[consultado el 15 de junio de 2018].

Huisa Téllez, José Carlos 2014. "Representaciones sociales a través del lenguaje en la lexicografía hispanoamericana decimonónica”, Boletín de Filología, 49, 2, pp. 139-159.

Langer, Nils \& Agnete Nesse 2014. "Linguistic purism", en The Handbook of historical sociolinguistics. Eds. Juan M. Hernández-Campoy \& J. Camilo Conde-Silvestre, Wiley-Blackwell, Malden, pp. 607-625.

Lara, Luis Fernando 1997. Teoría del diccionario monolingüe, El Colegio de México, México.

Lara, Luis Fernando 2011. "El símbolo, el poder y la lengua", en El dardo en la Academia. Eds. Silvia Senz y Montserrat Alberde, Melusina, Barcelona, t. 1, pp. 315-341.

León-Portilla, Miguel 1981. "Otro testimonio de aculturación hispanoindígena: los nahuatlismos en el castellano de España”, Revista Española de Antropología Americana, 11, pp. 219-244.

López Morales, Humberto 1991. Sociolingüistica, Gredos, Madrid.

Martínez Baracs, Rodrigo 2001. "Acerca del origen de la palabra gringo", Biblioteca de México, 62/63, pp. 98-103.

Milroy, James 2014. "Sociolinguistics and ideologies in language history", en The Handbook of historical sociolinguistics. Eds. Juan M. Hernández-Campoy \& J. Camilo Conde-Silvestre, Wiley-Blackwell, Malden, pp. 571-584.

Moreno Fernández, Francisco 2009. Principios de sociolingüistica y sociología del lenguaje, $4^{\mathrm{a}}$ ed. corr. y actualizada, Ariel, Barcelona. 
Navarro Carrasco, Ana Isabel 2000. La Academia y los americanismos de "La tía Julia y el escribidor", Universidad de Alicante, Alicante.

Navarro Carrasco, Ana Isabel 2011. "América y la Academia: americanismos que faltan en el DRAE-01”, Revista de Investigación Lingüistica, 14, pp. 215-245.

Ramos i Duarte, Félix 1895. Diccionario de mejicanismos. Colección de locuciones $i$ frases viciosas, con sus correspondientes críticas $i$ correcciones fundadas en autoridades de la lengua; máximas, refranes, provincialismos y retoques populares de todos los estados de la república mejicana, Imprenta de Eduardo Dublan, Méjico.

RoJAs, DARío 2011. "Indicaciones contrastivas en Voces usadas en Chile (1900) de Aníbal Echeverría y Reyes”, Revista Argentina de Historiografía Lingüistica, 3, 1, pp. 67-77.

Santamaría, Francisco J. 2000 [1959]. Diccionario de mejicanismos, 6 a ed., Porrúa, Méjico.

SenZ, Silvia 2011. "Una, grande y (esencialmente) uniforme. La RAE en la conformación y expansión de la «lengua común»", en El dardo en la Academia. Eds. Silvia Senz y Montserrat Alberde, Melusina, Barcelona, t. 2, pp. 9-302.

Toro y Gisbert, Miguel De s.f. [1912?]. Americanismos, Ollendorf, Paris, http:/ /bdh-rd.bne.es/viewer.vm?id=0000038981\&page $=1$ [consultado el 21 de marzo de 2019].

Zimmermann, Klaus 2003. "El fin de los diccionarios de americanismos. La situación de la lexicografía del español de América después de la publicación de los Diccionarios contrastivos del español de América", Revista Internacional de Lingüistica Iberoamericana, 1, pp. 71-83.

ZimmermanN, Klaus 2012. "Diccionarios, identidad e ideología lingüística. Una reseña y evaluación comparativa del Diccionario del español de México y del Diccionario de mexicanismos", Revista Internacional de Lingüistica Iberoamericana, 19, pp. 167-181. 
